\section{Some Remarks on the Dhaulagiri Journal of Sociology and Anthropology (Volume II)}

\section{Ram B. Chhetri}

Before I make my comments on volume II of the Dhaulagiri Journal of Sociology and Anthropology (DJSA), I would like to say a few words about the Department of Sociology/Anthropology (DOSA) at Mahendra Multiple Campus (MMC) in Baglung and the teachers here who are responsible for the production of this journal. Most of the teachers in the department of Sociology/Anthropology here were educated at the Central Department in Kirtipur. A couple of them also have obtained other degrees-including M. Phil from University of Bergen, Norway. With such credentials, they chose to work in a far flung township in the Dhaulagiri region of western Nepal. In many ways, this campus and its teachers are geographically located far away from current sources of research based knowledge on their subjects-i.e., the books, journals, magazines, etc., that are disseminated from the 'centres' of publication in big cities. But that did not seem to worry this campus and its teachers. In stead of complaining that they have no easy access to information, MMC and the teachers of this department are now able to tell everyone that if you have a goal and the will to achieve it, if you work hard with determination, you too can participate in the act of knowledge production and dissemination from a very remote place also in today's world. I congratulate DOSA (MMC) Editor-in-Chief as well as the team of editors of this journal to have set an example of good work.

Now let me move on to make some comments on DJSA. This is not a review of the journal in question-and therefore, I am not going to make any comments on the conceptual, substantive and methodological aspects of the papers included in this volume. I will give a brief introduction of the contents of the journal but then urge the readers to find out for themselves as to what kind of detailed findings are presented in each of the papers. I will also let the readers make their own judgment on the academic value or the application of the knowledge that has been assembled by the authors. After introducing the papers briefly, I will make some general comments about how the quality of the journal could be improved by the editors in the days to come.

There are a total of twelve papers included in this issue of the DJSA and the contributions report studies from Nepal, Bangladesh and Nigeria. The paper by Dahal presents a general discussion about social science and its context in Nepal. Another paper by Uprety supports a common idea that it is better to build on what is already out there-i.e., learn from traditional and indigenous knowledge and practicesrather than expend energy in reinventing the same wheel time and again. The other papers included in this volume deal with some specific issues of relevance to different fields and subfields in the social sciences. For instance the papers by Bakke and Subedi (on Nepal); Ojikutu (on Nigeria); and Rahman (on Bangladesh) deal with issues that are pertinent in the fields of medical sociology or anthropology. Similarly, some papers deal with issues of births and deaths (Oestigaard; P. Acharya) while others deal with issues of inclusion and exclusion (Rawal), migration of elderly people (Gautam), the relationship between monuments and the perceptions of 
ethnic identity (Khattri), a general discussion of development (B. Acharya) and ethno-ecology (Sapkota). In short, the papers provide materials that would be of interest to readers with various and specialized fields of interest within the social sciences.

The DJSA and its team of editors must be admired for being mindful of some of the technical facets of a journal publication. Taking advantage of the present day advances in internet technology, they have made arrangements for the contents of the journal to be uploaded into NepJol. This goes in support of the idea that knowledge and information has to be made public - to be made accessible to anyone who is interested in these. The editors must also be appreciated for obtaining separate ISSN for the print and online versions of the journal (some other sociology/anthropology departments of TU have not bothered to get ISSN for their journals!). Since it is available on-line, a publication from a small town located in the laps of Mount Dhaulagiri will now be read by researchers, academics, students and other interested individuals from any part of the globe. The editors have also invited scholars as well as researchers from anywhere in the world to join them-by choosing to publish their works in DJSA.

Before I conclude this comment I would now like to make some suggestions-so that the future volumes of DJSA become even better. It would be nice if the editors could ask the authors to submit their final papers after editing the language (i.e., check the grammar and make the text legible), fixing the typographical errors (there are a lot of typos in the papers), and completing the references as per citations in their respective papers. Finally, the footnotes/endnotes for introducing the contributions of the papers become superfluous when there is already sufficiently detailed biographical information on the authors provided under a separate section on 'Contributors'.
Once again, I must admire the teachers of DOSA (MMC), Baglung for their efforts towards publishing a journal of their own. For me, this publication gives a loud and clear message that all you need in order to do something good is that you should be ready to take the initiative, have some positive ideas, and commitments. In spite of being far away from the 'centre' the faculty members at Baglung have shown that with your imagination, appropriate initiative, good thinking and hard work you can reach everyone out there as well as those at the centre. That is, your own efforts only can make you a part of the game (of knowledge production, sharing and/or dissemination) and enable you to become connected and be noticed. 